\title{
Alpha-Aminoadipic Acid Measurement
}

National Cancer Institute

\section{Source}

National Cancer Institute. Alpha-Aminoadipic Acid Measurement. NCI Thesaurus. Code C154761.

The determination of the amount of alpha-aminoadipic acid present in a sample. 